\title{
Deprived Neighbourhoods in Transition: Divergent Pathways of Change in the Greater Manchester City- Region
}

\author{
Stephen Hincks
}

\author{
School of Environment, Education and Development \\ University of Manchester, \\ Oxford Road, \\ Manchester, \\ M13 9PL
}

Stephen.hincks@manchester.ac.uk

\section{Forthcoming in Urban Studies 2015 (Online First)}

DOI: $10.1177 / 0042098015619142$

\begin{abstract}
Many studies of neighbourhood change adopt a 'bookend' mode of analysis in which a baseline year is identified for a chosen outcome variable from which the magnitude of change is calculated to a determined end-point typically over bi-decadal or decadal timeframes. However, this mode of analysis smooths-away short-run change patterns and neighbourhood dynamics. The implications of this practice could be far reaching if it is accepted that as neighbourhoods change they are liable to cross a threshold and transition from one state to another in the short as well as longer-term. In a case study of deprived neighbourhoods in the Greater Manchester city-region, this paper aims to contribute to neighbourhood change debates in two ways. The first is by isolating transition pathways for individual neighbourhoods using annual change data. The second is by testing the thesis that the more deprived a neighbourhood is, the more likely it is to respond with greater volatility to short-run shocks when compared to less-deprived neighbourhoods. Four indicators collected annually between 2001 and 2010 are used to develop a typology of neighbourhood change and a subsequent typology of neighbourhood transition. The analysis exposed 260 different transition pathways that deprived neighbourhoods followed over the study period. Multinomial logistic regression was then used to determine the odds of a neighbourhood undergoing transition along a specific pathway owing to its level of deprivation. The model revealed that the most deprived neighbourhoods were likely to follow more volatile transition pathways compared to the less-deprived neighbourhoods especially during periods of economic difficulty.
\end{abstract}




\section{Introduction}

The study of neighbourhood change can be traced back to the 1920s when members of the pioneering Chicago School first began analysing the sociological structure of cities and their neighbourhoods. In the now extensive North American literature on neighbourhood change, it has been posited that as neighbourhoods are exposed to different exogenous and endogenous forces, they are liable to change and, in doing so, cross a threshold and transition from one state to another (Schelling, 1971; Denton and Massey, 1991; Reibel and Regelson, 2007). In the UK, there has been sustained academic and policy interest in neighbourhood change with much of this focusing on understanding the geography of deprivation and the efficacy of urban policy interventions to address the persistent spatial clustering of deprivation. Since the 1970s, this focus has underpinned the development of several official indices designed to measure deprivation. However, these indices have been widely criticised because they provide only a 'snapshot' measure of deprivation and have therefore been ineffective at capturing change over time (Norman, 2010) ${ }^{i}$.

Studies that have sought to move beyond these official indices and measure change in deprived neighbourhoods have often adopted a 'bookend' mode of analysis in which a baseline year is identified for a chosen outcome variable from which the magnitude of change is calculated to a determined end-point. Generally, this mode of analysis has involved the adoption of bi-decadal or decadal timeframes that focus on medium or long-run change patterns and their underlying dynamics (e.g. Orford, 2004; Schultz-Baing and Wong, 2012; Hincks, 2015). However, the dominance of this approach has served to limit our understanding of short-run change in deprived neighbourhoods and as a consequence little attention has been afforded to understanding the mechanisms and patterns associated with the transition of deprived neighbourhoods between different states over time.

Through a case study of the Greater Manchester city-region, this paper aims to respond to these deficiencies and contribute to neighbourhood change debates in two ways. The first is by demonstrating the value of capturing patterns of annual change in deprived neighbourhoods and then using these to isolate transition pathways for individual neighbourhoods or groups of neighbourhoods over time. Similar 'pathway' approaches have been applied in other contexts and have proven effective at capturing variability in the trajectories of change taken by different neighbourhoods (e.g. Séguin et al, 2012; Hwang and Sampson, 2014). The second contribution is by testing the thesis that the more deprived a neighbourhood is, the more likely it is to respond with greater volatility to short-run shocks when compared to less-deprived neighbourhoods. Whilst this corresponds to broader interpretations of the vulnerabilities of disadvantaged neighbourhoods to changing endogenous and exogenous effects (Atkinson and Kintrea, 2001; Kearns and Parkes, 2003; Cole, 2013; Hwang and Sampson, 2014), there remains little understanding of how disadvantaged and vulnerable neighbourhoods respond to shocks in the short-run (Galster and Tatian, 2009).

The approach used to analyse change and transition in this paper consists of several components. First, using four change indicators, a typology is developed to capture the trajectory of annual change taken by neighbourhoods relative to one another across the city-region for the period 2001 to 2010. The typology is then subjected to two-step cluster analysis in order to determine the structure of deprived neighbourhood change over time. The resulting clusters are used to further classify neighbourhoods according to whether they follow one of three transition pathways: monostate, dual-state or multi-state transition. Finally, multinomial logistic regression is used to explore the relationship between transition pathways and levels of neighbourhood deprivation. In structuring the analysis, three research questions are explored:

1. How have deprived neighbourhoods in the Greater Manchester city-region changed annually between 2001 and 2010?

2. What are the patterns of deprived neighbourhood transition in the city-region between 2001 and 2010? 
3. To what extent is the likelihood that neighbourhoods in the city-region will undergo transition along a specific pathway affected by the level of neighbourhood deprivation?

The next section positions the study within the context of existing literature on neighbourhood change and transition. The third section outlines the case study context and methodology. The fourth section reports the results of the analysis. The final section discusses the results in the context of the research questions and explores avenues for future research.

\section{Neighbourhood Change}

In seeking to understand neighbourhood change, it is first necessary to define what is meant by a 'neighbourhood'. The literature covering this issue is voluminous - spanning early conceptions of natural areas proposed by urban social ecologists (Park, 1936) through to more contemporary sociospatial and institutional definitions (Galster, 2001; Webster, 2003). Galster's (2001: 2112) definition of a neighbourhood as a "...bundle of spatially based attributes associated with clusters of residences, sometimes in conjunction with other land uses" is particularly attractive for the purposes of this research because of its scope and comprehensiveness in recognising the spatial and sociological structure of neighbourhoods.

As conceptions of the neighbourhood have evolved and understanding of the processes that drive change has developed, so a variety of heuristic models and frameworks have emerged (see Grigsby, 1963; Schwirian, 1983; Grigsby et al, 1987; Temkin and Rohe, 1996). In broad terms, these models recognise that neighbourhood change is driven by the interactions of endogenous (e.g. demographic and socioeconomic characteristics; levels of deprivation and poverty; housing stock; and service provision) and exogenous factors (national policy agendas; macroeconomic performance; and national housing market functioning). The accumulation of these interactive effects can serve to reinforce the existing condition of a neighbourhood or to alter its condition resulting in the upgrading or downgrading of the neighbourhood over time.

This latter scenario might be induced through the introduction of a systemic shock that disrupts an established pattern of change for a particular neighbourhood or group of neighbourhoods (Galster et al, 2007). Such a shock is likely to be felt most acutely in the short-run with ripple effects manifesting over the medium or long-run ii as the neighbourhood gradually 'resets' to its original trajectory of change or conversely shifts to an entirely different one (see Meen, 2009). Alternatively, the interaction of various exogenous and endogenous factors might generate relatively marginal changes to the condition of a neighbourhood over the short-term but these changes will accumulate incrementally over the medium and long-run (Galster et al, 2007).

\section{Neighbourhood Transition}

Although the process of neighbourhood change is ongoing, it is not necessarily a linear or uniformly constant process. The recognition that as a neighbourhood changes, it is liable to cross a threshold or 'tipping point' and transition from one state to another can be traced back to theories of invasion, succession, and filtering (see Grigsby, 1963; Schelling, 1971). Neighbourhood transition gained particular currency in early studies of racial change in North American cities. One model developed by Wurdock (1981) conceived a three stage mode of transition: the penetration of a minority of nonwhite pioneers into a neighbourhood; invasion as in-movers took up residence in the neighbourhood with existing - often white - residents 'fleeing'; and consolidation as the neighbourhood moves from one dominant ethnic composition to another.

Yet the literature on threshold effects is fragmented and disparate. In a wide-ranging review, Quercia and Galster (2000) found evidence of inherent threshold effects in the dynamics of various neighbourhood attributes. The authors subsequently went on to define a threshold effect as "...a dynamic process in which the magnitude of the response changes significantly as the triggering stimulus exceeds some critical value" (p. 146). In successive studies, threshold effects were found to 
exist as neighbourhoods exceeded certain 'critical values' on chosen outcome indicators, leading to more rapid change in neighbourhood conditions over time (Galster et al, 2000; Galster et al, 2007).

In an extension to this area of research, subsequent studies have focused on elucidating 'pathways' of neighbourhood transition - the variable trajectories of change as neighbourhood conditions evolve and subsequently exceed the notional 'critical value' (Hwang and Sampson, 2014). Drawing on various housing, demographic and socioeconomic indicators covering four US cities between 1970 and 2010, Delmelle (2015) found that neighbourhoods followed distinctive pathways of change as they transitioned between various states over time (also see Séguin et al, 2012). In this context, it was revealed that migration served to exacerbate levels of polarisation between historically disadvantaged neighbourhoods, as changing populations and socioeconomic compositions altered the transition pathways of disadvantaged neighbourhoods. Taking a different perspective on transition, Galster and Tatian (2009) used annual housing market data to analyse the responses of disadvantaged neighbourhoods in Washington D.C. to house price appreciation at a specific 'tipping point'. The analysis revealed that disadvantaged neighbourhoods often experienced rapid and substantial house price appreciation during buoyant times only to be exposed to adverse market conditions during economically challenging periods.

This body of research on neighbourhood change and transition offers various lessons that can be used to frame the empirical focus of this study. From the literature it is evident that neighbourhoods can assume different states depending on their underlying structures or dynamics (Galster et al, 2007; Delmelle, 2015). Invariably, these states can reflect a neighbourhood's performance on a particular indicator (e.g. income level) or set of indicators (e.g. composite index) that can be measured in absolute or relative terms against an established baseline. However, irrespective of the measure that is ultimately adopted, it is apparent that in certain contexts a neighbourhood will undergo change and exceed a critical threshold - possibly resulting from a shock or the accumulation of change effects - and transition from one state to another (Quercia and Galster, 2000). In other contexts, as a neighbourhood changes in response to a shock or accumulated change effects, it will not exceed a critical threshold. In this instance, the neighbourhood will transition within the same steady-state (see Galster et al, 2007). The implication here is that neighbourhoods will transition along various pathways as endogenous and exogenous forces generate variable trajectories of change over time (Seguin et al, 2012; Hwang and Sampson, 2014; Delmelle, 2015). In light of this understanding, the paper proposes that the following features be incorporated into a methodological framework to measure patterns and trends in neighbourhood transition:

- The adoption of an appropriate timeframe to structure the analysis;

- The definition of a standard suite of neighbourhood units;

- The identification of temporal indicators to measure neighbourhood change dynamics over the chosen timeframe;

- The identification of analytical 'devices' to define appropriate thresholds and to measure neighbourhood transition over time.

The next section outlines the case study context before these principles are operationalised in the methodology.

\section{Study Context}

\section{Case Study}

Greater Manchester is a post-industrial city-region located in North West England. It comprises ten local authority districts and, according to the 2011 Census, has a population of 2.68million. In March 2015, Greater Manchester was granted City Deal status by central government. Building on previous rounds of decentralisation, this will see the devolution of various budgetary and governance responsibilities - including strategic planning, transport, infrastructure and health spending - to the 
Greater Manchester Combined Authority. With a history of successful political brokerage to draw on, the city-region elites have long-been held up as pioneers of city-branding, urban entrepreneurialism, and the development of models of territorial governance that are more cohesive than in most comparable UK cities (see Harding et al, 2010). The so called 'Manchester Miracle' - a reference to the disputed renaissance experienced by Manchester and its wider city-region over the past couple of decades - is said to have been driven by agglomerative economic growth (see MIER, 2009; Harding et al, 2010). However, this pursuit of a model of agglomeration-led growth has fuelled questions regarding the equity of the economic transformation and sustainability of the (Greater) Manchester experience (Deas, 2014).

These questions have been particularly pointed because of the experience of the cityregion's most deprived neighbourhoods which have been targeted through decades of national and local regeneration efforts. In the 1990s, City Challenge and the Single Regeneration Budget (SRB) offered particularly important streams of funding for (Greater) Manchester. In the 2000s, New Deal for Communities (NDC), the Neighbourhood Renewal Fund (NRF), and Housing Market Renewal (HMR) were all rolled-out across the city-region, targeting variously deprived parts of the city. The total expenditure on these projects is difficult to calculate when European and other match funding is taken into consideration but, focusing only on central government expenditure, between 1992 and 2010 over $£ 1.5$ billion was targeted towards deprived areas of the city-region.

These interventions were intended to help narrow the gap between deprived and lessdeprived neighbourhoods in Greater Manchester. Yet despite the scale of these interventions, the city-region continues to be characterised by sustained levels of socio-spatial polarisation that are more marked than in any of the other principal provincial cities of England (see Russell et al, 2009). Greater Manchester therefore provides an ideal case study in which to test the transition pathways approach as a means of capturing variation in the change trajectories of deprived neighbourhoods over time.

\section{Identifying Deprived Neighbourhoods}

Lower Super Output Areas (LSOAs) have been adopted in this research as proxy neighbourhoods. LSOAs are official census units used in England but they accord with Galster's (2001) definition of neighbourhoods being defined by population size (approximately 1500 people), contiguity and social homogeneity. LSOAs were also chosen for their practical benefits. LSOA boundaries remained stable for data published prior to the 2011. In addition, a range of data was released at LSOA level for the timeframe covered by the study. This included the Index of Multiple Deprivation (IMD) which has long-been used in England to represent the 'official' geography of deprivation at neighbourhood leveliii.

Although the IMD has been critiqued for its ineffectiveness at tracking changes at the neighbourhood level, it nevertheless provides a mechanism for demarcating 'more-deprived' from 'less-deprived' neighbourhoods. In this study, the 2004 iteration of the English IMD was adopted as the deprivation measure ${ }^{\mathrm{iv}}$. This index draws on a range of indicators covering various domains: income, employment, health and disability, education skills and training, barriers to housing and other services, crime and living environment. The indicators for each domain are weighted and combined to generate a domain score. The domain scores are then weighted and combined to form a composite measure of deprivation for each neighbourhood. This is then used to rank each LSOA from one (most deprived) through to 32482 (least deprived) (see Noble et al, 2006 for details of the methodology). As a continuous measure of relative deprivation, no definitive cut-off exists to delineate 'deprived' from 'less-deprived' areas but other studies have adopted $10 \%$ or $20 \%$ thresholds (e.g. Robson et al, 2008; Schultz-Baing and Wong, 2012). A 20\% cut-off was used in this study. Of the 20\% most deprived LSOAs in England ( $n=6496), 635$ were located in Greater Manchester (Figure 1). 


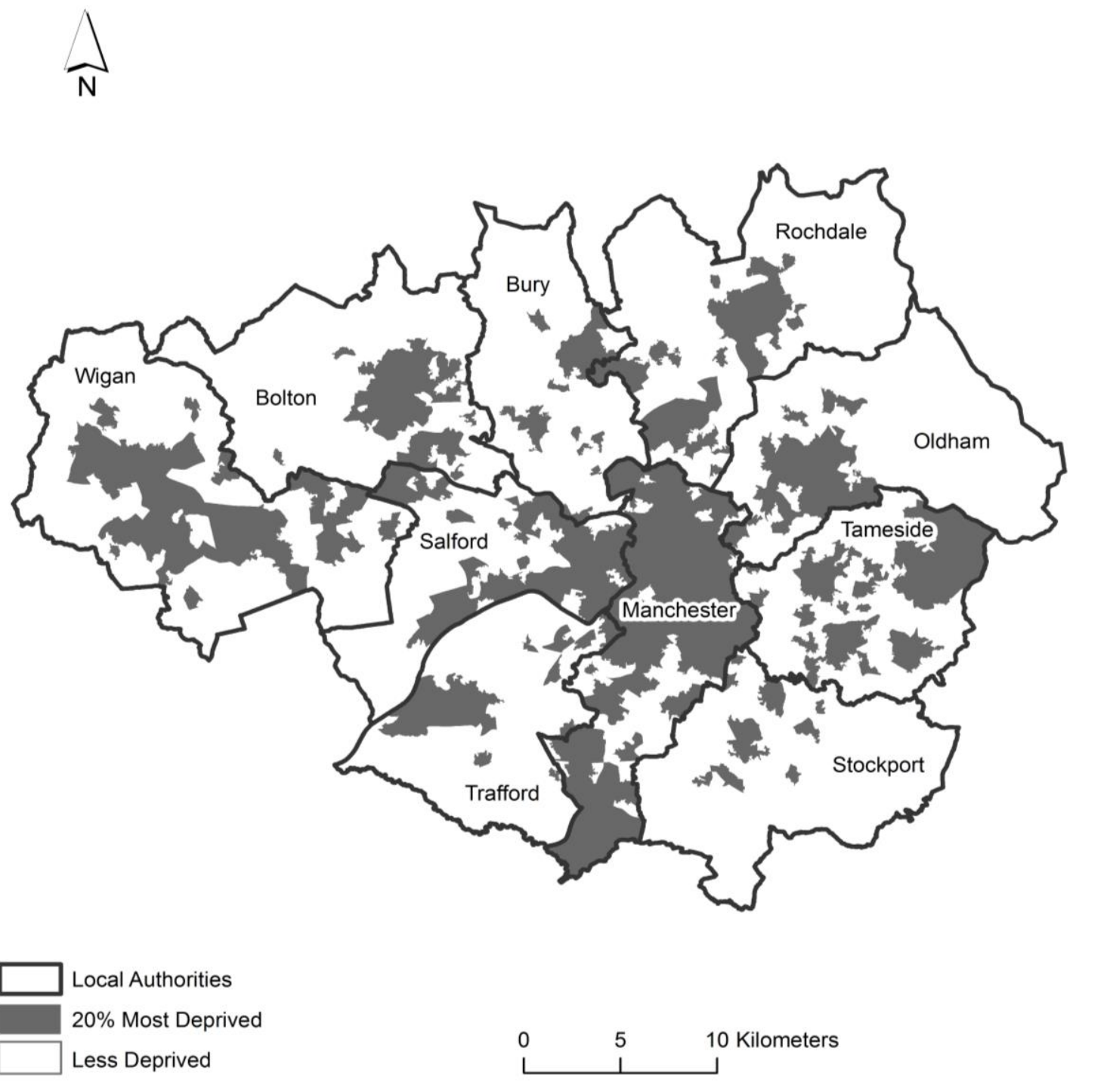

\section{Methodology}

This section outlines the methodology that was developed to analyse deprived neighbourhood transition in Greater Manchester, summarised in Figure 2.

\section{Step1: Developing a Typology of Neighbourhood Change}

The first stage of the methodology involved developing a typology to capture patterns of neighbourhood change. The first step in developing the typology involved identifying indicators to measure change annually between 2001 and 2010. A range of national administrative datasets were audited and indicators were assessed against three criteria:

- Conceptual underpinnings of the indicator and its relevance to understanding change in a deprived neighbourhood context;

- Availability of the indicator on an annual-basis over the selected timeframe at LSOA level or below;

- Legacy of the indicator being applied in policy and/or policy evaluations at neighbourhood level in the UK. 

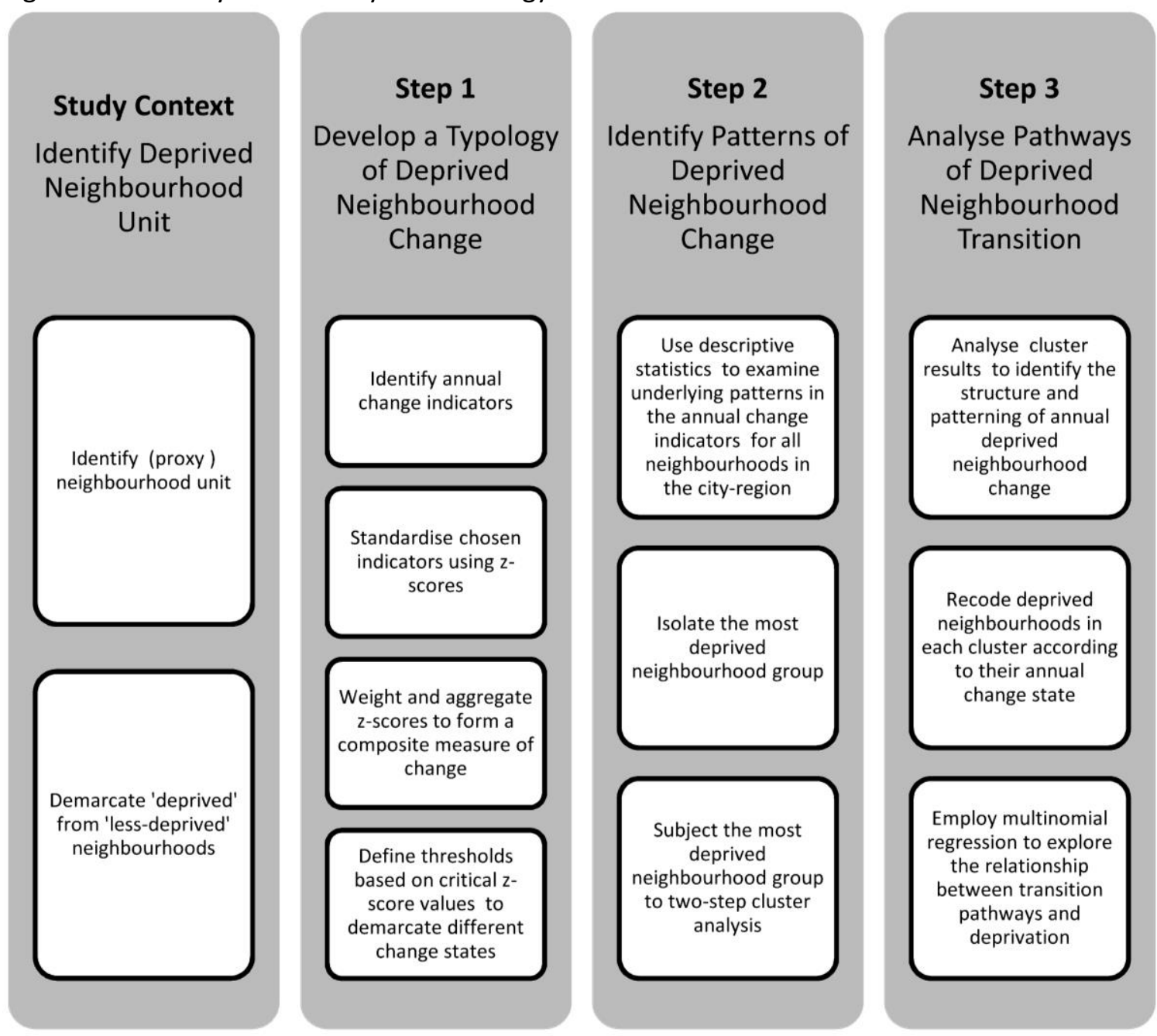

Four indicators were identified through this exercise (Table 1). The next step involved processing the indicators before generating the change typology. Two key considerations underpinned the conception of the typology. The first was whether the typology should capture absolute or relative change. In this instance, the typology was intended to be used to measure annual change in deprived neighbourhoods relative to all neighbourhoods in the city-region. As such, the typology needed to cover all 1646 LSOAs in Greater Manchester. The rationale for developing a typology of relative change was two-fold. The IMD is a measure of relative deprivation and so the intention was to locate the analysis within this same analytical tradition. By measuring relative change, it was possible to identify moments when deprived neighbourhoods diverged from the cityregion 'average' as well as moments of convergence as neighbourhoods followed various transition pathways (Hwang and Sampson, 2014; Delmelle, 2015).

The second consideration related to the definition of different neighbourhood states. These needed to be defined on an annual-basis which required the identification of thresholds to demarcate states based on annual neighbourhood change trajectories. It was important that the thresholds were defined consistently for each year so that the change states in one year (e.g. 20012002) were comparable to other years (e.g. 2005-2006). In light of these two considerations, the four change indicators were subject to standardisation using z-scores. Rather than converting each indicator separately for each year - which would have produced inconsistent thresholds as z-score values reflected the distribution of change data for each year - the four indicators were converted concurrently in a single calculation. This created a score for each indicator for each neighbourhood that was relative for each year. The converted z-scores were then subjected to sensitivity analysis 
using Pearson Correlation which did not reveal any problematic instances of excessive correlation. The four converted indicators were then weighted equally before linear aggregation was used to form a single composite variable. This captured annual change for each neighbourhood relative to all other neighbourhoods in the city-region between 2001 and 2010 . The thresholds delineating three change categories were defined using critical $z$-score values for a two-tailed test ${ }^{v}$ :

1) Above Average $(z=\geq 1.00)$

2) Average $(z=<1.00>-1.00)$

3) Below Average $(z=\leq-1.00)$

Table 1: Neighbourhood Change Indicators

\begin{tabular}{|c|c|c|c|}
\hline Variable & Conceptual Considerations & Analytical Interpretation & $\begin{array}{l}\text { Legacy of Use in } \\
\text { Policy or Evaluation } \\
\text { Studies }\end{array}$ \\
\hline $\begin{array}{l}\text { 1) Change in } \\
\text { working age } \\
\text { population^ } \\
\text { claiming job } \\
\text { seekers } \\
\text { allowance } \\
(\mathrm{JSA})(\%)^{*}\end{array}$ & $\begin{array}{l}\text { JSA is a commonly used measure of social distress. It has often been } \\
\text { used to capture unemployment but it has been shown that JSA only } \\
\text { records a fraction of real unemployment particularly in areas of } \\
\text { long-term unemployment (see Beatty and Fothergill, 2002). } \\
\text { Nevertheless, JSA has been recorded over a long period of time and } \\
\text { LSOA level and is a broadly acceptable compromise for capturing } \\
\text { labour market participation. }\end{array}$ & $\begin{array}{l}\text { Decline in JSA represented } \\
\text { improvement in the } \\
\text { social/economic } \\
\text { conditions of a } \\
\text { neighbourhood. An } \\
\text { increase was seen to } \\
\text { represent a worsening of } \\
\text { conditions (Hincks and } \\
\text { Robson, 2010). }\end{array}$ & $\begin{array}{l}\text { JSA was used as a key } \\
\text { performance } \\
\text { indicator of change in } \\
\text { the evaluation of the } \\
\text { National Strategy for } \\
\text { Neighbourhood } \\
\text { Renewal (NSNR) for } \\
\text { England (DCLG, } \\
\text { 2010). }\end{array}$ \\
\hline $\begin{array}{l}\text { 2) Change in } \\
\text { population } \\
\text { annually } \\
2001-2010 \\
(\%)^{*}\end{array}$ & $\begin{array}{l}\text { A stated aim of UK government urban policy over the past } 20 \text { years } \\
\text { has been to encourage people to move back into cities. Much of the } \\
\text { regeneration effort during that time was focused on redeveloping } \\
\text { brownfield land much of it located in deprived neighbourhoods. } \\
\text { Population change was used here as a proxy of changing location } \\
\text { desirability. Ideally, change in vacancy rates would have been } \\
\text { preferable - a widely applied measure in North America (see Galster } \\
\text { et al, 2003) - but micro-scale vacancy data is limited in the UK. } \\
\text { Population change was measured at LSOA level using the Office for } \\
\text { National Statistics' post-censal small area population estimates of } \\
\text { the usual resident population as at } 30 \text { June each year. The versions } \\
\text { used were published before the } 2011 \text { census and as such were } \\
\text { classified as 'experimental statistics'. They have since been subject } \\
\text { to revision following the publication of the } 2011 \text { Census. } \\
\text { Nevertheless, the experimental versions have proved robust when } \\
\text { applied in similar analyses (see Schultz-Baing and Wong, 2012). }\end{array}$ & $\begin{array}{l}\text { Population growth } \\
\text { represented improvement } \\
\text { whilst a fall in population } \\
\text { was seen to be a feature of } \\
\text { neighbourhood decline } \\
\text { (Hincks and Robson, 2010). }\end{array}$ & $\begin{array}{l}\text { Population change at } \\
\text { neighbourhood level } \\
\text { featured in the } \\
\text { National Review of } \\
\text { Housing market } \\
\text { Renewal Pathfinders } \\
\text { (2005-2007) (DCLG, } \\
\text { 2009) }\end{array}$ \\
\hline $\begin{array}{l}\text { 3) Change in } \\
\text { housing } \\
\text { transaction } \\
\text { rates per } 100 \\
\text { transactions } \\
\text { in the period } \\
2001-2010 \\
(\%) \text { at LSOA } \\
\text { level** }\end{array}$ & $\begin{array}{l}\text { Housing sales data provide a measure of aggregate realised demand } \\
\text { for housing. It is also a useful proxy indicator of the confidence held } \\
\text { by consumers in the wider housing market that is being realised in a } \\
\text { particular neighbourhood (Mallach, 2008). The transaction indicator } \\
\text { was derived by aggregating individual transactions each year to } \\
\text { LSOA level which were then converted into a rate per } 100 \\
\text { transactions in the period } 2001-2010 \text {. This indicator can be } \\
\text { challenging to interpret. Low transactions might be seen to capture } \\
\text { either market stability or alternatively sluggishness. High transaction } \\
\text { rates could reflect a market that encourages transience - perhaps } \\
\text { reflecting gentrification - or 'fire sales' as a result of transition to } \\
\text { alternative states (e.g. ethnic or racial transition). The use of } \\
\text { transaction rates was intended to control for any potential volatility } \\
\text { owing to small sample sizes at the LSOA level. }\end{array}$ & $\begin{array}{l}\text { An increase in transactions } \\
\text { was taken to represent } \\
\text { increasing vibrancy in the } \\
\text { neighbourhood whilst a } \\
\text { drop in transactions was } \\
\text { taken to represent a } \\
\text { decline in vibrancy } \\
\text { (Mallach, 2008). }\end{array}$ & $\begin{array}{l}\text { Housing transaction } \\
\text { change at } \\
\text { neighbourhood level } \\
\text { featured in the } \\
\text { National Review of } \\
\text { Housing market } \\
\text { Renewal Pathfinders } \\
\text { (2005-2007) (DCLG, } \\
2009)\end{array}$ \\
\hline $\begin{array}{l}\text { 4) Change in } \\
\text { median } \\
\text { house prices } \\
(\%) \text { at LSOA } \\
\text { level** }\end{array}$ & $\begin{array}{l}\text { House prices measure the relative health of the housing market. } \\
\text { House prices reflect macroeconomic circumstances, the condition of } \\
\text { the built environment, and neighbourhood attractiveness among } \\
\text { other factors (Mallach, 2008). The house price indicator was derived } \\
\text { by calculating a median for each LSOA based on individual } \\
\text { transactions each year. The median was adopted because the } \\
\text { median provides greater stability than the mean and is less } \\
\text { susceptible to the effects of extreme values. }\end{array}$ & $\begin{array}{l}\text { An increase in house price } \\
\text { represented improvement } \\
\text { whilst a fall was seen to } \\
\text { represent decline. (Hincks } \\
\text { and Robson, 2010). }\end{array}$ & $\begin{array}{l}\text { Median house price } \\
\text { change at } \\
\text { neighbourhood level } \\
\text { featured in the } \\
\text { National Review of } \\
\text { Housing market } \\
\text { Renewal Pathfinders } \\
\text { (2005-2007) (DCLG, } \\
\text { 2009) }\end{array}$ \\
\hline
\end{tabular}

Source* Neighbourhood Statistics (http://www.neighbourhood.statistics.gov.uk/dissemination/)

** Land Registry Price Paid Data (http://www.landregistry.gov.uk/market-trend-data)

Note: ^ Defined as 16-64 for males and 16-59 for females - calculated annually using post-censal small area population estimates 


\section{Step2: Identifying Patterns of Deprived Neighbourhood Change}

The next step involved analysing patterns of deprived neighbourhood change in the city-region. Descriptive statistics were initially employed to analyse underlying patterns in the four indicators used to define the change typology. All LSOAs in the city-region were divided into three groups using the 2004 IMD: the $20 \%$ most deprived nationally; the $20 \%$ least deprived nationally; and the remaining neighbourhoods in the city-region. Trends in three indicators (No.1, 2 and 4) were analysed using ANOVA - a test that is appropriate for variables with mean values - and trends in one indicator (No.3) were analysed using Kruskal-Wallis - a test that is appropriate for variables with median values (Table 1). The aim of the exercise was to determine whether there were significant differences between deprived and less-deprived neighbourhoods across the different indicators.

Following this preliminary analysis, the deprived neighbourhood group - the $20 \%$ most deprived LSOAs - was isolated and two-step cluster analysis was employed in an attempt to identify patterns of change specifically for this group. Two-step cluster analysis was adopted because it can accommodate the categorical data that was used to reflect the different neighbourhood states in the change typology. The first step in determining an optimum cluster solution involved the identification of pre-clusters. The pre-clusters were generated through the allocation of cases - in this instance deprived LSOAs - to a group consisting of other deprived LSOAs with similar change properties to the target LSOA. The aim of this first step was to minimise within and maximise between-cluster distances. The log-likelihood distance measure was used to assess the similarity of the pre-clusters and the Schwartz Bayesian Criterion (BIC) was used to determine the number of preclusters that would be generated.

In the second stage, an agglomerative clustering algorithm was used to group the preclusters. Again, the aim here was to minimise within and maximise between-cluster distances. The number of clusters was determined using the auto-clustering algorithm in SPSS. A range of cluster solutions were generated and BIC values were used to identify the optimum cluster solution. An initial test was undertaken in which all years (nine variables) were included in a single run. Different outlier thresholds were tested but the diagnostic BIC values consistently revealed that the various cluster solutions were of poor quality. As a result, different combinations of coterminous years were subsequently tested (e.g. 2001 and 2002; 2001, 2002 and 2003 and so on) and outlier thresholds were adjusted ${ }^{\text {vi }}$. The aim of the exercise was to improve the quality of the cluster solutions that were generated whilst minimising outlier thresholds so that as many cases (LSOAs) were included in a cluster as possible.

\section{Step 3: Analysing Pathways of Deprived Neighbourhood Transition}

The groups of neighbourhoods, identified as part of the two-step cluster analysis, were then used to develop a subsequent neighbourhood transition typology. This involved re-coding the LSOAs in each cluster by identifying whether the LSOA passed through one of three transition trajectories:

1. Mono-state transition - the neighbourhood sustained the same transition pathway each year (e.g. above average to above average).

2. Dual-state transition - the transition pathway is comprised of two different states (e.g. above average and average). The neighbourhood might transition regularly or irregularly between these two states over time.

3. Multi-state transition - the transition pathway is comprised of the three different states (e.g. above average, average, and below average). The neighbourhood might transition regularly or irregularly between these different states over time.

Finally, multinomial logistic regression was employed to explore the relationship between these transition pathways and levels of neighbourhood deprivation. In this part of the analysis, the $20 \%$ most deprived neighbourhood group was divided into two sub-groups to enable the demarcation of variable levels of deprivation. The first sub-group was comprised of those LSOAs in 
the $10 \%$ most deprived neighbourhoods nationally (herein referred to as the $10 \%$ decile group). The second sub-group included the remaining neighbourhoods that were between the $10 \%$ and $20 \%$ deprivation deciles nationally (herein referred to as the $20 \%$ decile group). This deprived neighbourhood categorisation was adopted as the dependent variable and the transition typology was adopted as the independent variable. Diagnostic statistics indicated no problems regarding overdispersion or multicollinearity in the data ${ }^{\text {vii. }}$. The resulting regression model was built to focus on measuring the main effects of the transition typology on levels of neighbourhood deprivation. The aim was to test whether being more or less-deprived increased the odds of neighbourhoods following a specific transition pathway or not in different periods.

\section{The Structure of Deprived Neighbourhood Change}

The trends in the four untransformed indicators used to construct the neighbourhood change typology are detailed in Table 2. The results demonstrate that with the exception of population change for the first three consecutive years of the study period, house price change in 2001-2002 and 2007-2008, and transaction change in 2004-2005, 2005-2006, 2007-2008, and 2009-2010, a significant difference was observed between the deprived and less-deprived neighbourhood groups in the change indicators.

The two-step cluster analysis (see Table 3 ) revealed three distinct periods of change (Figure 3). The first spans the years 2001 to 2004. In this period, the dominant pattern of change was one in which neighbourhoods were following a change trajectory consistent with the average for the cityregion over the ten-year timeframe. The ancillary pattern was one in which a higher proportion of neighbourhoods were experiencing above average rather than below average change. During this period, the proportion of the former ranged from $23 \%$ to $28 \%$ whilst the latter ranged from $14 \%$ to $17 \%$ respectively. The descriptive statistics reveal that on average during this first period deprived neighbourhoods were gaining population, experiencing house price inflation and rising transaction rates and, with the exception of 2003-2004, declining JSA claimant rates.

These trends are likely to reflect a number of factors. Many deprived neighbourhoods in the city-region had long-suffered from depressed housing market functioning and comparatively high levels of labour market inactivity. As a result, three of the fours indicators used to construct the change typology (house prices, transactions and JSA) were measured from a depressed baseline position meaning 'positive' change would likely be magnified in the trends. In fact, JSA claimant rates have remained stubbornly high in deprived neighbourhoods in Greater Manchester despite recording statistically significant levels of decline over this first phase (see Hincks, 2015).

The trends in the change data could also reflect the 'lagged' effects of the regeneration initiatives that were rolled-out across the city-region during the 1990s and early 2000 s (see the earlier 'case study' section). It was beyond the scope of this paper to evaluate the different impacts of these various interventions on deprived neighbourhoods in the city-region (instead see Robson et al, 1999; Squires, 2009; Turcu, 2012). However, research has suggested that regeneration efforts helped to enhance developer and investor confidence in deprived neighbourhoods at a time when urban policy was charged with delivering brownfield redevelopment alongside economic and social improvements in the most disadvantaged places, including Greater Manchester (see Schultz-Baing

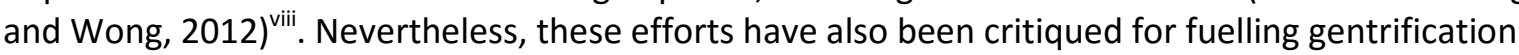
(e.g. Lees, 2008; Turcu, 2012) and for increasing the vulnerability of deprived neighbourhoods to the vagaries of the market (Hincks, 2015). Concomitantly, the change trends could also reflect the then emerging effects of the 'New Urban Policy' regime - extricated by Swyngedouw et al (2002) - that was serving to extend and reinforce the competitive position of the Greater Manchester economy. This has since been consolidated in the Greater Manchester model and its now established agglomeration-centric economic growth agenda (see Deas, 2014). 
Table 2: Results for Change Indicators - 2001-2010

\begin{tabular}{|c|c|c|c|c|c|c|c|c|c|c|c|c|}
\hline \multirow[b]{2}{*}{ Year } & \multicolumn{3}{|c|}{ Population Change $^{\mathrm{a}}$} & \multicolumn{3}{|c|}{ Median House Price Change } & \multicolumn{3}{|c|}{$\begin{array}{l}\text { Housing Transaction Rate } \\
\text { Change }^{\mathrm{a}}\end{array}$} & \multicolumn{3}{|c|}{ JSA Change ${ }^{a}$} \\
\hline & Mean & Range & SD. & Median & Range & SD. & Mean & Range & SD. & Mean & Range & SD. \\
\hline $\begin{array}{l}2001- \\
2002\end{array}$ & $\begin{array}{l}0.05 \\
0.14 \\
-0.07 \\
\end{array}$ & $\begin{array}{l}6.76 \\
19.78 \\
31.15 \\
\end{array}$ & $\begin{array}{l}1.22 \\
\frac{2.06}{2.90}\end{array}$ & $\begin{array}{l}16.86 \\
17.35 \\
14.43\end{array}$ & $\begin{array}{l}123.52 \\
\underline{187.23} \\
\mathbf{3 2 6 . 1 6}\end{array}$ & $\begin{array}{l}18.57 \\
\underline{19.30} \\
\mathbf{3 2 . 2 8}\end{array}$ & $\begin{array}{l}0.69^{*} \\
\frac{1.41}{2.10}\end{array}$ & $\begin{array}{l}23 \\
\frac{34}{40} \\
\end{array}$ & $\begin{array}{l}3.56 \\
3.91 \\
4.56\end{array}$ & $\begin{array}{l}0.08^{*} \\
-0.04 \\
-0.23 \\
\end{array}$ & $\begin{array}{l}3.43 \\
4.55 \\
5.83\end{array}$ & $\begin{array}{l}0.57 \\
\underline{0.66} \\
\mathbf{0 . 9 8}\end{array}$ \\
\hline $\begin{array}{l}2002- \\
2003\end{array}$ & $\begin{array}{l}0.21 \\
0.29 \\
0.46\end{array}$ & $\begin{array}{l}8.00 \\
19.00 \\
38.00 \\
\end{array}$ & $\begin{array}{l}1.41 \\
1.90 \\
2.93\end{array}$ & $\begin{array}{l}22.00^{*} \\
\frac{25.00}{27.00}\end{array}$ & $\begin{array}{l}100.00 \\
290.00 \\
646.00\end{array}$ & $\begin{array}{l}15.97 \\
21.45 \\
\mathbf{4 3 . 8 3} \\
\end{array}$ & $\begin{array}{l}-1.13^{*} \\
\frac{-0.58}{\mathbf{0 . 9 9}}\end{array}$ & $\begin{array}{l}21 \\
\frac{36}{61} \\
\end{array}$ & $\begin{array}{l}3.80 \\
4.32 \\
5.16\end{array}$ & $\begin{array}{l}-0.10^{*} \\
-0.12 \\
-\mathbf{0 . 2 4}\end{array}$ & $\begin{array}{l}2.38 \\
4.13 \\
6.75 \\
\end{array}$ & $\begin{array}{l}0.48 \\
0.61 \\
0.95\end{array}$ \\
\hline $\begin{array}{l}2003- \\
2004\end{array}$ & $\begin{array}{l}0.01 \\
0.15 \\
\mathbf{0 . 3 1}\end{array}$ & $\begin{array}{l}7.00 \\
20.00 \\
53.00 \\
\end{array}$ & $\begin{array}{l}1.42 \\
\frac{2.02}{2.85}\end{array}$ & $\begin{array}{l}16.00^{*} \\
\underline{23.00} \\
35.00\end{array}$ & $\begin{array}{l}93.00 \\
175.00 \\
393.00\end{array}$ & $\begin{array}{l}15.23 \\
\underline{18.75} \\
\mathbf{3 4 . 6 7}\end{array}$ & $\begin{array}{l}0.15^{*} \\
\underline{-0.29} \\
0.38\end{array}$ & $\begin{array}{l}27 \\
\frac{38}{82} \\
\end{array}$ & $\begin{array}{l}4.00 \\
4.22 \\
6.00 \\
\end{array}$ & $\begin{array}{l}-0.21^{*} \\
-0.20 \\
\mathbf{0 . 6 5}\end{array}$ & $\begin{array}{l}1.96 \\
5.22 \\
7.01 \\
\end{array}$ & $\begin{array}{l}0.44 \\
0.61 \\
0.99\end{array}$ \\
\hline $\begin{array}{l}2004- \\
2005\end{array}$ & $\begin{array}{l}-0.20^{*} \\
\frac{-0.15}{\mathbf{0 . 9 0}}\end{array}$ & $\begin{array}{l}7.00 \\
17.00 \\
38.00\end{array}$ & $\begin{array}{l}1.32 \\
1.85 \\
2.89\end{array}$ & $\begin{array}{l}6.00^{*} \\
10.00 \\
19.00\end{array}$ & $\begin{array}{l}82.00 \\
157.00 \\
481.00\end{array}$ & $\begin{array}{l}14.86 \\
16.23 \\
31.02\end{array}$ & $\begin{array}{r}-2.16 \\
-2.83 \\
-2.44\end{array}$ & $\begin{array}{l}27 \\
\frac{42}{74}\end{array}$ & $\begin{array}{l}.94 \\
4.25 \\
5.99\end{array}$ & $\begin{array}{l}0.02^{*} \\
0.11 \\
0.35\end{array}$ & $\begin{array}{l}2.36 \\
4.12 \\
7.47\end{array}$ & $\begin{array}{l}0.50 \\
0.62 \\
0.94\end{array}$ \\
\hline $\begin{array}{l}2005- \\
2006\end{array}$ & $\begin{array}{l}-0.28^{*} \\
-0.01 \\
\mathbf{0 . 7 9}\end{array}$ & $\begin{array}{l}43.00 \\
22.00 \\
43.00 \\
\end{array}$ & $\begin{array}{l}3.09 \\
2.55 \\
3.75\end{array}$ & $\begin{array}{l}5.00^{*} \\
\underline{6.00} \\
11.00\end{array}$ & $\begin{array}{l}92.00 \\
\frac{288.00}{271.00}\end{array}$ & $\begin{array}{l}15.80 \\
\underline{16.92} \\
\mathbf{2 3 . 7 6}\end{array}$ & $\begin{array}{l}2.75 \\
2.55 \\
1.98\end{array}$ & $\begin{array}{l}26 \\
\frac{41}{75} \\
\end{array}$ & $\begin{array}{r}4.31 \\
\frac{4.04}{6.24} \\
\end{array}$ & $\begin{array}{l}0.01^{*} \\
\underline{0.15} \\
\mathbf{0 . 5 0}\end{array}$ & $\begin{array}{r}2.30 \\
4.57 \\
7.57 \\
\end{array}$ & $\begin{array}{l}0.47 \\
0.60 \\
1.01\end{array}$ \\
\hline $\begin{array}{l}2006- \\
2007\end{array}$ & $\begin{array}{l}0.03^{*} \\
0.04 \\
\mathbf{0 . 8 5}\end{array}$ & $\begin{array}{l}9.00 \\
22.00 \\
26.00\end{array}$ & $\begin{array}{l}1.42 \\
2.02 \\
2.93\end{array}$ & $\begin{array}{l}7.00^{*} \\
7.00 \\
9.00\end{array}$ & $\begin{array}{l}175.00 \\
127.00 \\
142.00\end{array}$ & $\begin{array}{l}16.60 \\
12.81 \\
\mathbf{1 5 . 4 1}\end{array}$ & $\begin{array}{l}-0.61^{*} \\
\frac{-0.12}{\mathbf{0 . 5 2}}\end{array}$ & $\begin{array}{l}20 \\
\frac{39}{59} \\
\end{array}$ & $\begin{array}{r}3.53 \\
4.33 \\
6.47\end{array}$ & $\begin{array}{l}-0.06^{*} \\
\frac{-0.10}{\mathbf{0 . 2 6}}\end{array}$ & $\begin{array}{l}3.22 \\
3.91 \\
5.78\end{array}$ & $\begin{array}{l}0.53 \\
0.59 \\
\mathbf{0 . 8 8}\end{array}$ \\
\hline $\begin{array}{l}2007- \\
2008\end{array}$ & $\begin{array}{l}-0.04^{*} \\
\underline{0.30} \\
\mathbf{0 . 8 4}\end{array}$ & $\begin{array}{l}8.00 \\
21.00 \\
26.00\end{array}$ & $\begin{array}{l}1.39 \\
2.11 \\
3.05\end{array}$ & $\begin{array}{l}-3.50 \\
-3.00 \\
-2.00\end{array}$ & $\begin{array}{l}98.00 \\
173.00 \\
150.00\end{array}$ & $\begin{array}{l}14.57 \\
15.56 \\
\mathbf{1 5 . 9 9}\end{array}$ & $\begin{array}{l}-5.79 \\
0.71 \\
-6.40\end{array}$ & $\begin{array}{l}14 \\
\frac{40}{49} \\
\end{array}$ & $\begin{array}{r}2.83 \\
3.66 \\
5.55\end{array}$ & $\begin{array}{l}0.12^{*} \\
\underline{0.35} \\
\mathbf{0 . 4 1}\end{array}$ & $\begin{array}{l}2.70 \\
4.21 \\
6.16\end{array}$ & $\begin{array}{l}0.57 \\
0.63 \\
0.92\end{array}$ \\
\hline $\begin{array}{l}2008- \\
2009\end{array}$ & $\begin{array}{l}-0.05^{*} \\
0.54 \\
0.99 \\
\end{array}$ & $\begin{array}{l}10.00 \\
22.00 \\
36.00\end{array}$ & $\begin{array}{l}1.50 \\
1.89 \\
2.90\end{array}$ & $\begin{array}{l}-8.00^{*} \\
-8.00 \\
-12.00\end{array}$ & $\begin{array}{l}147.00 \\
\underline{155.00} \\
\mathbf{1 0 3 4 . 0 0} \\
\end{array}$ & $\begin{array}{l}20.76 \\
\underline{18.35} \\
\mathbf{4 4 . 8 6} \\
\end{array}$ & $\begin{array}{l}0.71^{*} \\
-0.71 \\
-2.10 \\
\end{array}$ & $\begin{array}{l}13 \\
\frac{28}{68} \\
\end{array}$ & $\begin{array}{l}2.51 \\
2.86 \\
4.34 \\
\end{array}$ & $\begin{array}{l}-0.23^{*} \\
-0.68 \\
-2.21 \\
\end{array}$ & $\begin{array}{l}\frac{3.25}{4.66} \\
16.48\end{array}$ & $\begin{array}{l}\frac{0.67}{0.69} \\
\underline{1.45} \\
\end{array}$ \\
\hline $\begin{array}{l}2009- \\
2010\end{array}$ & $\begin{array}{l}0.23^{*} \\
0.54 \\
1.48\end{array}$ & $\begin{array}{l}7.00 \\
25.00 \\
32.00 \\
\end{array}$ & $\begin{array}{l}1.40 \\
2.07 \\
3.03\end{array}$ & $\begin{array}{l}4.50^{*} \\
\frac{3.00}{-2.00}\end{array}$ & $\begin{array}{l}118.00 \\
214.00 \\
246.00\end{array}$ & $\begin{array}{l}18.75 \\
19.52 \\
\mathbf{2 5 . 3 3}\end{array}$ & $\begin{array}{l}0.38 \\
0.30 \\
0.39\end{array}$ & $\begin{array}{l}15 \\
\frac{20}{88} \\
\end{array}$ & $\begin{array}{l}2.59 \\
2.32 \\
4.34\end{array}$ & $\begin{array}{l}0.81^{*} \\
\frac{1.64}{4.16}\end{array}$ & $\begin{array}{l}3.99 \\
\frac{5.90}{19.56}\end{array}$ & $\begin{array}{l}0.65 \\
0.93 \\
1.70\end{array}$ \\
\hline
\end{tabular}

Note: a) Measured using one-way ANOVA; (b) Measured using Kruskal-Wallis test ${ }^{*} \mathrm{p}<0.01(\mathrm{n}=1646)$

Italic - 20\% least deprived; Bold - 20\% most deprived; underlined - remaining neighbourhoods

Figure 3: Trends in Deprived Neighbourhood Change - 2001-2010

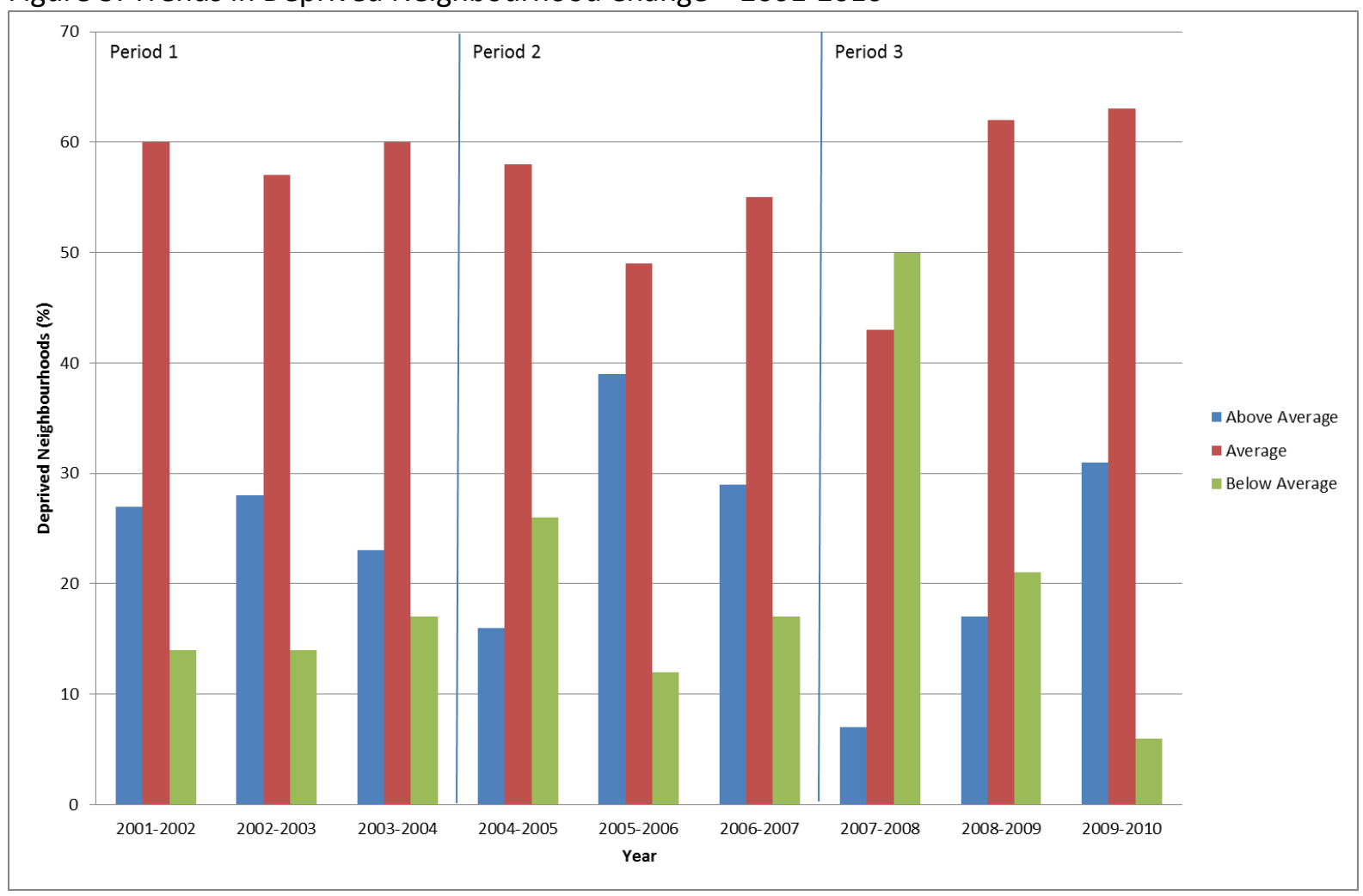


The second period extends from 2004 to 2007. The dominant pattern here was one in which neighbourhoods were experiencing change that was consistent with the average for the city-region over the ten-year timeframe. The ancillary pattern was one in which more-deprived neighbourhoods experienced above average rather than below average change, except for 2004-2005 when this trajectory was interrupted. This relatively minor shock can be traced back to the functioning of the housing market between 2004 and 2006. During this period, the macroeconomy was in a state of inflation, so much so that in the summer of 2004, the Bank of England raised interest rates for the fifth time in nine months. This had the effect of quelling household spending which ultimately fed into the mortgage market. In response, mortgage lending fell in 2005 reflecting widespread speculation that the national housing market was showing signs of slow-down (see Cave and Giles, 2005). In 2004-2005, median house prices in the $20 \%$ most deprived neighbourhoods in the cityregion were averaging a $19 \%$ increase but this was in contrast to the previous year when increases were recorded at $35 \%$. At the same time, average transaction rates in deprived neighbourhoods had also declined. This shock interrupted the change patterns of a segment of the $20 \%$ most-deprived neighbourhoods as they tipped from an above average or average to a below average trajectory of change.

Finally, the third period extends from 2007 to 2010. In this period, deprived neighbourhoods were subject to intense shock brought on by the global financial crisis, after which there is evidence of 'relative rebound' towards average and above average trajectories of change. In 2007-2008, the proportion of neighbourhoods experiencing above average change plummeted from $29 \%$ in 2006 2007 to $7 \%$ in 2007-2008. At the same time, the proportion of neighbourhoods experiencing below average trajectories of change soared from $17 \%$ to $50 \%$. Between 2007-2008 and 2009-2010, the proportion of neighbourhoods experiencing average change one year and average change the next increased by $20 \%$ whilst change from below average one year to below average the next declined from $50 \%$ to $7 \%$ in the same period. The proportion of neighbourhoods experiencing above average change also increased from $7 \%$ in $2007-2008$ to $31 \%$ in $2009-2010$ suggesting that in relative terms deprived neighbourhoods 'rebounded' soon after the initial shock brought on by the financial crisis.

However, these trends reflect little more than a consolidation of a much worsened position rather than any concerted recovery in the aftermath of the initial impacts of the financial crisis. As expected, the immediate impacts of the crisis were felt most acutely in the housing market between 2007 and 2009. The descriptive statistics demonstrate that median house prices, having risen by $9 \%$ in 2006-2007, declined by $2 \%$ in 2007-2008. Transaction rates plummeted by $6.4 \%$ in $2007-2008$ whilst JSA increased by $0.4 \%$. House prices fell by a further $12 \%$ in $2008-2009$ reflecting lagged effects of the recession as these filtered into the housing market data. Moreover, although transactions performed better than the previous year, they were still depressed when compared to pre-recession levels. House prices continued to fall in 2009-2010 - albeit to a lesser extent than the previous year - and whilst transactions increased, the gains made were marginal. Ultimately the housing market, having been decimated by the crisis had seemingly reached the bottom of the trough and had experienced a degree of consolidation by the end of the decade. Although population continued to increase on average across deprived neighbourhoods in the third period, trends in JSA were highly volatile. Having declined by $2.2 \%$ in 2008-2009, JSA increased in 2009-2010 by $4.2 \%$. In terms of the latter, this seemingly reflects the lagged transmission of recessionary impacts into the labour market as economic inactivity in the most vulnerable neighbourhoods deepened. The relative measure of change, coupled with the descriptive statistics measuring absolute change, reveals a context in which 2009-2010 was a period that was comparatively 'lessextreme' than 2007-2008 and 2008-2009 as the majority of neighbourhoods stabilised - albeit many in a worsened state than before 2007. Alongside this stabilisation, some deprived neighbourhoods improved relative to other neighbourhoods as this stabilising effect pushed them into a marginally improving state. 
The next section examines the relationship between these trends in neighbourhood change and the associated patterns of transition across the suite of deprived neighbourhoods in Greater Manchester.

\section{Transition Pathways of Deprived Neighbourhoods}

The results of the two-step cluster analysis demonstrate that deprived neighbourhood transition is a complex and variegated process (Table 3). Between 2001 and 2010, 260 discrete transition pathways were identified across the suite of deprived neighbourhoods and $70 \%$ of all pathways $(n=184)$ were comprised of a single neighbourhood carving its own unique transition trajectory.

Table 3: Results of the Two-Step Cluster Analysis

\begin{tabular}{|c|c|c|c|c|}
\hline Years & Cluster & Cluster Configuration & Transition Type & \% Neighbourhoods* \\
\hline $2001-02$ & 1 & $\leftrightarrow \uparrow \leftrightarrow$ & Dual & 8 \\
\hline 2002-03 & 2 & $\downarrow \leftrightarrow \leftrightarrow$ & Dual & 4 \\
\hline \multirow[t]{7}{*}{$2003-04$} & 3 & $\leftrightarrow \leftrightarrow \leftrightarrow$ & Mono & 26 \\
\hline & 4 & $\uparrow \leftrightarrow \leftrightarrow$ & Dual & 9 \\
\hline & 5 & $\leftrightarrow \leftrightarrow \uparrow$ & Dual & 7 \\
\hline & 6 & $\leftrightarrow \leftrightarrow \downarrow$ & Dual & 5 \\
\hline & 7 & $\leftrightarrow \downarrow \leftrightarrow$ & Dual & 4 \\
\hline & 8 & $\leftrightarrow \uparrow \downarrow$ & Multi & 4 \\
\hline & Outliers & 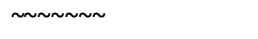 & Variable & 33 \\
\hline 2004-05 & 1 & $\leftrightarrow \uparrow \leftrightarrow$ & Dual & 11 \\
\hline $2005-06$ & 2 & $\uparrow \uparrow \downarrow$ & Dual & 3 \\
\hline \multirow[t]{9}{*}{ 2006-07 } & 3 & $\downarrow \leftrightarrow \uparrow$ & Multi & 3 \\
\hline & 4 & $\leftrightarrow \leftrightarrow \uparrow$ & Dual & 8 \\
\hline & 5 & $\leftrightarrow \uparrow \uparrow$ & Dual & 6 \\
\hline & 6 & $\leftrightarrow \leftrightarrow \leftrightarrow$ & Mono & 18 \\
\hline & 7 & $\leftrightarrow \uparrow \downarrow$ & Multi & 5 \\
\hline & 8 & $\downarrow \uparrow \leftrightarrow$ & Multi & 6 \\
\hline & 9 & $\downarrow \leftrightarrow \leftrightarrow$ & Dual & 9 \\
\hline & 10 & $\leftrightarrow \leftrightarrow \downarrow$ & Dual & 4 \\
\hline & Outliers & 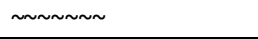 & Variable & 28 \\
\hline $2007-08$ & 1 & $\leftrightarrow \leftrightarrow \uparrow$ & Dual & 8 \\
\hline 2008-09 & 2 & $\downarrow \leftrightarrow \uparrow$ & Multi & 9 \\
\hline \multirow[t]{6}{*}{$2009-10$} & 3 & $\downarrow \leftrightarrow \leftrightarrow$ & Dual & 22 \\
\hline & 4 & $\downarrow \leftrightarrow \uparrow$ & Multi & 5 \\
\hline & 5 & $\leftrightarrow \leftrightarrow \leftrightarrow$ & Mono & 19 \\
\hline & 6 & $\downarrow \downarrow \leftrightarrow$ & Dual & 6 \\
\hline & 7 & $\leftrightarrow \downarrow \leftrightarrow$ & Dual & 6 \\
\hline & Outliers & 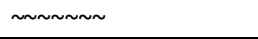 & Variable & 26 \\
\hline
\end{tabular}

The percentages are calculated based on the total of all deprived neighbourhoods in the city-region $(n=635)$.

In the first two periods (2001-2004 and 2004-2007), the primary transition pathway was comprised of deprived neighbourhoods following a mono-state trajectory that was consistent with the average for the city-region for the ten-year timeframe. In the first period, eight clusters were identified. Cluster three included $26 \%$ of neighbourhoods and was reflective of neighbourhoods undergoing average mono-state transition. The remaining seven clusters accounted for $41 \%$ of all neighbourhood transitions. These overwhelmingly reflect secondary dual-state pathways that were predominantly oscillating around the average but which in the short-run had been disrupted. The exception to this was the multi-state pathway captured by cluster eight (4\%). In this first period, onethird of transitions were classified in the outlier group and these reflected tertiary pathways.

In the second period, ten clusters were identified. Cluster six was the primary pathway and included $18 \%$ of neighbourhoods. This cluster was reflective of neighbourhoods undergoing monostate transition consistent with the city-region average. The remaining nine clusters reflect secondary transitions and accounted for $54 \%$ of all pathways in this period. Of these $41 \%$ were dualstate and $13 \%$ were multi-state pathways. During this period, less than one-third of transitions were confined to the outlier group as tertiary pathways.

In the final period, seven clusters were identified. There were two primary pathways identified in this final period. Cluster five included $19 \%$ of neighbourhoods experiencing average 
mono-state transition but this was countered somewhat by a similarly dominant dual-state transition - cluster three - in which $22 \%$ of neighbourhoods experienced below average performance followed by two years of transition that was consistent with the city-region average. In this period, $42 \%$ of transitions included in one of the main clusters were dual-state and $13 \%$ were multi-state reflecting secondary pathways. One quarter of neighbourhoods were included in the outlier group representing tertiary pathways.

With these structures in mind, multinomial logistic regression was used to analyse whether being more or less-deprived affected the odds of a neighbourhood transitioning along a mono-state, dual-state or multi-state pathway in the different periods identified through the cluster analysis. Of the 635 neighbourhoods included in the model, $62 \%$ were in the $10 \%$ decile group and $38 \%$ were in the $20 \%$ decile group. The $10 \%$ group was used as the reference category for the dependent variable and the dual-state category was used as the reference against which other transition types would be compared. These categories were chosen because they had the highest absolute counts helping to reduce the effects of errors in the model. A test of the full model against the constant only model was statistically significant with a Chi Square value of $36.55(\mathrm{df}=6)$ at $p<.000$. The overall prediction success of the model was $65 \%$. The -2 Log Likelihood statistics for the predictor variables were all significant $(p<.05)$ in explaining change across deprived neighbourhoods ${ }^{i x}$ and the parameter estimates also revealed significant effects of predictor variables on the dependent variable (Table 4).

Table 4: Multinomial Logistic Regression Model of Deprived Neighbourhood Transition

\begin{tabular}{|c|c|c|c|c|}
\hline Variable & B & $\operatorname{Exp}(B)$ & Sig. & Wald \\
\hline \multicolumn{5}{|l|}{ 20\% Decile Group } \\
\hline Intercept & -.943 & - & .000 & 34.11 \\
\hline \multicolumn{5}{|l|}{ Period 1 (2001-2004) } \\
\hline Mono-State Transition & .747 & 2.11 & .000 & 18.42 \\
\hline Multi-State Transition & .499 & 1.65 & .195 & 1.679 \\
\hline Dual-State Transition & - & - & - & - \\
\hline \multicolumn{5}{|l|}{ Period 2 (2004-2007) } \\
\hline Mono-State Transition & .588 & 1.80 & .001 & 10.387 \\
\hline Multi-State Transition & -.012 & .989 & .966 & .002 \\
\hline Dual-State Transition & - & - & - & - \\
\hline \multicolumn{5}{|l|}{ Period 3 (2007-2010) } \\
\hline Mono-State Transition & -.243 & .784 & .182 & 1.781 \\
\hline Multi-State Transition & -.797 & .451 & .013 & 6.173 \\
\hline Dual-State Transition & - & - & - & - \\
\hline \multicolumn{5}{|c|}{-2 log-likelihood: Period 1 (101.106); Period 2 (93.739); Period 3 (89.506) } \\
\hline
\end{tabular}

When comparing the $10 \%$ and $20 \%$ decile groups, the model revealed significant effects in a number of areas. It was found that the odds of neighbourhoods in the $20 \%$ decile group undergoing mono-state transition as opposed to dual-state transition in the first period were twice as high as for the $10 \%$ decile group. In the second period, the odds of neighbourhoods in the $20 \%$ decile group experiencing mono-state transition as opposed to dual-state transition were 1.8 times higher than for the $10 \%$ decile group. In the first and second periods, no significant effects were recorded between the level of deprivation and multi-state pathways. However, in the third period, the odds of neighbourhoods in the $20 \%$ decile group undergoing multi-state rather than dual-state transition were $55 \%$ lower than for neighbourhoods in the $10 \%$ decile group.

The results of the regression model reveal a number of important features of deprived neighbourhood transition. The first is that across the three periods, neighbourhoods in the $10 \%$ decile group exhibited greater tendency towards instability when compared to the $20 \%$ decile group. Of all neighbourhoods in the $20 \%$ decile group, $69 \%$ (first period) and $57 \%$ (second period) followed a mono-state pathway that tracked the city-region average. This was compared to $49 \%$ (first period) and $39 \%$ (second period) of all neighbourhoods in the $10 \%$ decile group. Although the contrast between the $10 \%$ and $20 \%$ groups was less extreme than during previous periods, the greater instability of the $10 \%$ decile group was still evident in the third period as dual and multi-state 
pathways came to dominate the transition profiles of this group of the most deprived neighbourhoods (Figure 4).

Figure 4: Patterns of Deprived Neighbourhood Transition - 2001-2010

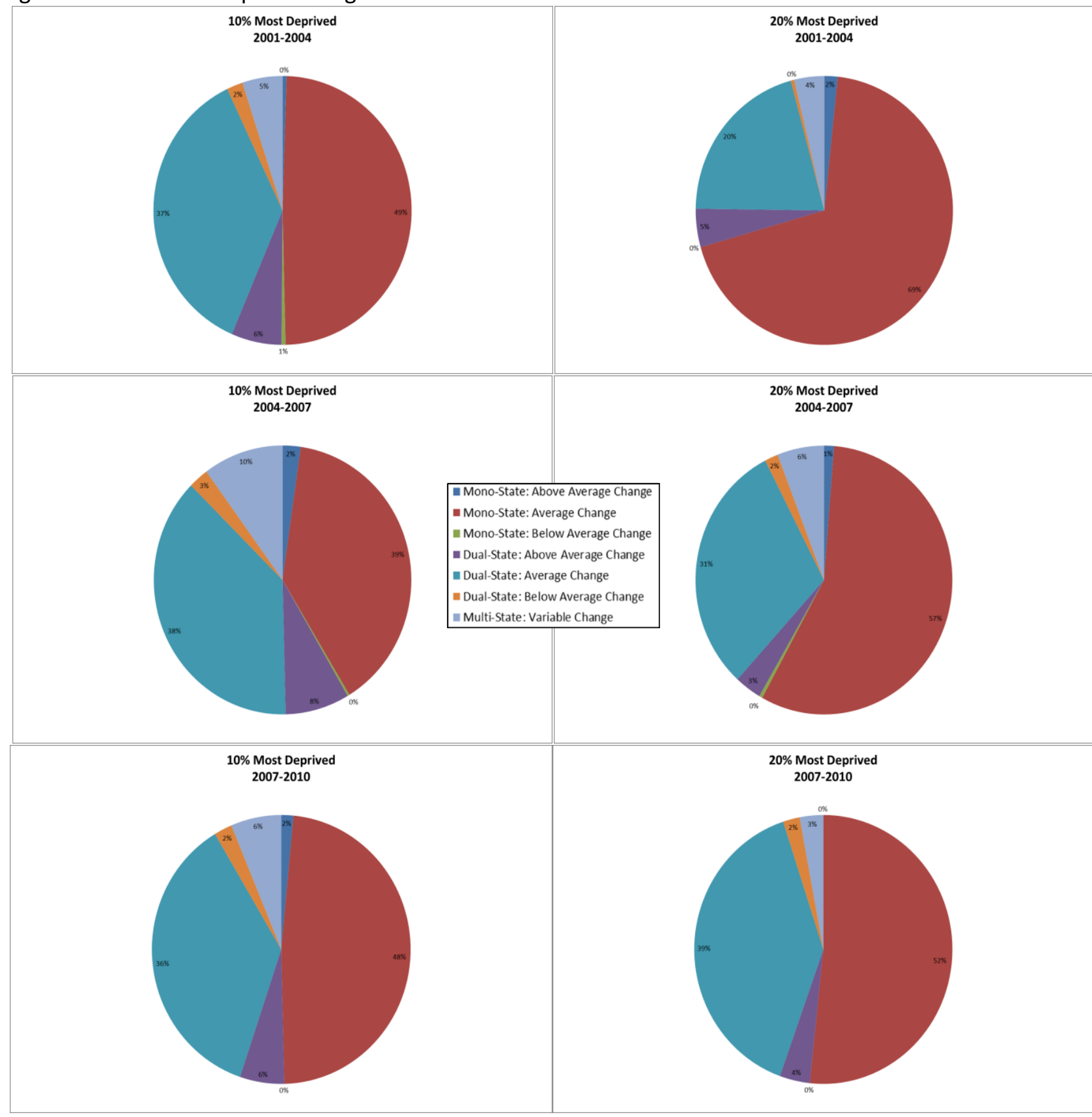

The second finding of note was that the two groups of deprived neighbourhoods responded in highly variable ways to shocks in the short-term. This is evident in two regards. The first is in the finding that during the second period, neighbourhoods in the $20 \%$ decile group were more likely to follow a mono-state than a dual-state transition when compared to the $10 \%$ group. This was a period in which the housing market was shocked by rising interest rates and the evidence suggests that this introduced greater variability in the $10 \%$ decile group compared to the $20 \%$ decile group. During this period, $41 \%$ of neighbourhoods in the $10 \%$ decile group followed a pathway that tracked the city-region average or that reflected above average performance across the entire period. This was in contrast to the $20 \%$ group in which $58 \%$ followed the same two pathways. The implication is that $59 \%$ of neighbourhoods in the $10 \%$ decile group followed more unstable dual or multi-state 
pathways compared to $42 \%$ of neighbourhoods in the $20 \%$ group (Figure 3 ). The second piece of evidence is the finding that during the third period - one characterised by intense 'shock' followed by 'consolidation' - neighbourhoods in the $10 \%$ decile group had greater odds of following more diverse and volatile multistate transition pathways when compared to neighbourhoods in the $20 \%$ decile group. Although the proportions are relatively small $-6 \%$ in the $10 \%$ decile group compared to $3 \%$ in the $20 \%$ decile group - the findings reflect the greater vulnerability of the most deprived neighbourhoods to exogenous effects (Figure 4).

Finally, the analysis demonstrates that important insights can be gained from understanding the 'noise' in the patterns of neighbourhood change and transition that are eroded in decadal or bidecadal modes of analyses. Clearly if the analysis had been structured on the conventional decadal or even bi-decadal timeframe, then the slow-down in the housing market in 2004-2005, not to mention the acute impacts of the 2007-2008 financial crisis would have remained hidden.

\section{Conclusion}

This paper has sought to provide an understanding of the patterns of deprived neighbourhood transition in the Greater Manchester city-region between 2001 and 2010. The analysis was structured around three research questions. The first part focused on answering the question: What is the structure of annual deprived neighbourhood change in the Greater Manchester city-region between 2001 and 2010? The results of the ANOVA and Kruskal-Wallis test revealed structural differences between deprived and less-deprived neighbourhoods in the city-region across the different indicators used to construct the change typology.

Cluster analysis was then used to unravel the structure of deprived neighbourhood change and in doing so revealed three distinct periods in the trend data. In the first and second periods, the trends suggest that deprived neighbourhoods were benefiting from the effects of externalities associated with Manchester's improving local economy which included gains in population - largely through migration - rising house prices, and added dynamism within housing sub-markets (see Schultz-Baing and Wong, 2012). They were also likely to be experiencing the positive and negative impacts of then contemporary regeneration interventions and the 'lagged' effects of interventions stemming from the 1990s (Deas, 2014). The third period was characterised by the shock of the 20072008 financial crisis followed by a period of 'relative rebound' in its aftermath. The typology of relative change, coupled with the descriptive statistics measuring absolute change, revealed a context in which 2009-2010 was a period that was comparatively 'less-extreme' than 2007-2008 and 2008-2009 as the majority of deprived neighbourhoods stabilised - albeit in a worsened state than

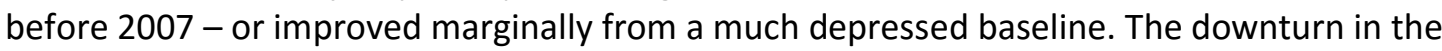
housing market was severe for deprived neighbourhoods but also significant was the lagged transmission of impacts in the labour market in 2009-2010.

The second part of the analysis focused on answering the question: 'What are the patterns of deprived neighbourhood transition in the city-region between 2001 and 2010? An initial analysis revealed a complex landscape of 260 different transition pathways for deprived neighbourhoods. Across the three periods, average state-to-average state transitions were the primary pathways. Nevertheless, there is evidence in the secondary and tertiary pathways that short-run variations were also characteristic features of deprived neighbourhood transition even if the dominant trend was towards the city-region average.

The final part of the analysis focused on the question: To what extent is the likelihood that neighbourhoods in the city-region will undergo transition along a specific pathway affected by the level of neighbourhood deprivation? Through this question, it was possible to test the thesis that the more deprived a neighbourhood was, the more likely it was to respond with greater volatility to short-term shocks when compared to less-deprived neighbourhoods. The analysis revealed that being more deprived did increase the odds of a neighbourhood experiencing greater volatility as a result of short-run shocks. In the second period, the $20 \%$ decile group were more likely to follow a mono-state than a dual-state transition when compared to the $10 \%$ group. In the third period, 
neighbourhoods in the $10 \%$ decile group were $45 \%$ more likely to follow diverse and volatile, multistate pathways than dual-state ones when compared to neighbourhoods in the $20 \%$ decile group.

At the 'aggregate' level, the analysis revealed a pattern of neighbourhood change that could conceivably be cast as a 'boom to bust' regime. During the first and second periods, the agglomerative forces rooted in the 'Manchester Model' - which sought to harness local and national growth potential - supported significant 'uplift' in neighbourhoods across the $10 \%$ and $20 \%$ decile groups respectively. However, the findings also suggest that the agglomerative growth model of Greater Manchester exposed the most-deprived neighbourhoods to the vicissitudes of the market as evidence by the acute 'downgrading' of neighbourhood performance and conditions during the third period. On the one hand, this vulnerability might well reflect the unintended consequences of wellmeaning policy attempts to 'unlock' latent potential in disadvantaged neighbourhoods by tapping into improvements in the local economy. On the other hand, these trends might also be read as evidence of the targeted exploitation of development opportunities within the most deprived neighbourhoods for profitable gains (Lees, 2008).

Whichever perspective is espoused, the 'boom to bust' narrative provides a powerful shorthand description of the broad patterns of change that characterised the $20 \%$ most deprived neighbourhoods in Greater Manchester between 2001 and 2010. Yet it must be acknowledged that this narrative is only part of the story of deprived neighbourhood change in the city-region. What is evident from the transition analysis is the diverse range of trajectories of change that were experienced by different deprived neighbourhoods at different points in time. Whilst convenient and accurate to an extent, the inherent risk in defaulting to the 'boom to bust' narrative is that it conceals the variable trajectories and dynamics of change that are characteristic of a group of neighbourhoods that are commonly treated as homogenous (also see Robson et al, 2008; Hincks, 2015).

In light of this analysis, there are various avenues that could be explored through further research. It has been suggested elsewhere that understanding narratives and personal histories of residents and stakeholders within a neighbourhood might offer more fruitful avenues for neighbourhood change research than approaches that aim "...to unlock causal paths or, in another familiar exercise, seek to derive neighbourhood "typologies" from an array of statistical indicators of various kinds" (Cole, 2013: 80). However, the analyses in this paper and elsewhere suggest that typological and modelling approaches can offer equally important insights into patterns of neighbourhood change and their underlying dynamics (Galster et al, 2007; Galster and Tatian, 2009; Huwang and Simpson, 2014; Hincks, 2015). Prospective studies should focus on mobilising multimethod frameworks that combine the narrative approach advocated by Cole and the transition approach adopted here and elsewhere. This would serve to add statistical breadth and interpretive depth to analyses of neighbourhood change and transition.

There are two particular research themes that immediately offer opportunities for the application of such a framework. The first is in studies seeking to understand the dynamic patterns of neighbourhood upgrading and downgrading and the second is in studies of neighbourhood or area effects. In both these contexts, the transition approach would provide a means of tracking patterns of neighbourhood change over time. These could then be linked to individual or household level perceptions and experiences of neighbourhoods as they undergo change. This would help respond to the criticism that too often studies of neighbourhood effects and dynamics of upgrading and downgrading have relied on static snapshots of neighbourhood conditions rather than longitudinal data that has the scope to capture the dynamics of changing neighbourhood contexts (see Atkinson and Kintrea, 2001; Teernstra and Van Gent, 2012; Van Ham et al, 2014).

Beyond these specifics areas of research, there are obvious benefits in extending the range of indicators used here to facilitate better understandings of neighbourhood transition trajectories. Finally, previous research has demonstrated the heterogeneity of deprived neighbourhoods in terms of their structures, compositions and trajectories of change (Robson et al, 2008; Rae, 2012; Hincks, 
2015). Future studies could explore ways of extending the focus of transition analyses beyond simple dichotomies of 'more-deprived' and 'less-deprived' by considering the transition pathways of different types of deprived neighbourhoods based on their underlying structures and functionalities among many other potential features.

\section{References}

Atkinson, R. and Kintrea, K. (2001) 'Disentangling Area Effects: Evidence from Deprived and NonDeprived Neighbourhoods' Urban Studies, 38, 2277-2298.

Beatty, C. and Fothergill, S. (2002) 'Hidden unemployment among men: a case study' Regional Studies, 36, 811-823.

Cave, F.T. and Giles, C. (2005) 'House Prices Wobble and Have a Long Way to Fall' Financial Times, 29 August.

Cole, I. (2013) 'Whose place? Whose history? Contrasting narratives and experiences of neighbourhood change and housing renewal' Housing, Theory and Society, 30(1), 65-83.

Deas, I. (2014) 'The search for territorial fixes in subnational governance: city-regions and the disputed emergence of post-political consensus in Manchester, England' Urban Studies, 51(11), 2285-2314.

Delmelle, E.C. (2015) 'Five decades of neighborhood classifications and their transitions: A comparison of four US cities, 1970-2010' Applied Geography 57, 1-11.

Denton, N.A. and Massey, D.S. (1991) 'Patterns of Neighbourhood Transition in a Multiethnic World: U.S. Metropolitan Areas, 1970-1980' Demography, 28(1), 41-63.

Department for Communities and Local Government (DCLG) (2009) National Evaluation of Housing Market Renewal Pathfinders 2005-2007. London, HMSO.

DCLG (2010) Evaluation of the National Strategy for Neighbourhood Renewal: Final Report. London, HMSO.

Galster, G. (2001) 'On the nature of neighbourhood' Urban Studies, 38, 2111-2124.

Galster, G. and Tatian, P. (2009) 'Modelling Housing Appreciation Dynamics in Disadvantaged Neighborhoods' Journal of Planning Education and Research, 29, 7-22.

Galster, G.C., Quercia, R.G. and Cortes, A. (2000) 'Identifying neighborhood thresholds: an empirical exploration' Housing Policy Debate, 11, 701-732.

Galster, G., Cutsinger, J. and Lim, U. (2007) 'Are Neighbourhoods Self-stabilising? Exploring Endogenous Dynamics' Urban Studies, 44(1), 167-185.

Galster, G.C., Quercia, R.G., Cortes, A. and Malega, R. (2003) 'The Fortunes of Poor Neighbourhoods' Urban Affairs Review, 39(2), 205-226.

Grigsby, W.G. (1963) Housing Markets and Public Policy. Philadelphia, University of Pennsylvania Press.

Grigsby, W., Baratz, M., Galster, G. and Maclennan, D. (1987) 'The Dynamics of Neighbourhood Change and Decline' Progress in Planning, 28, 1-76.

Harding, A., Harloe, M. and Rees, J. (2010) 'Manchester's Bust Regime' International Journal of Urban and Regional Research, 34(4), 981-991.

Hincks, S. (2015) 'Spatial Change and Deprived Neighbourhoods in the Greater Manchester CityRegion' Environment and Planning A, 47(2), 430-449.

Hincks, S. and Robson, B. (2010) Regenerating Communities First Neighbourhoods in Wales. York, JRF.

Hwang, J. and Sampson, R.J. 'Divergent Pathways of Gentrification: Racial Inequality and the Social Order of Renewal in Chicago Neighbourhoods' American Sociological Review, 79(4), 726-751.

Kearns, A. and Parkes, A. (2003) 'Living in and leaving poor neighbourhood conditions in England' Housing Studies, 18, 827-840.

Lees, L. (2008) 'Gentrification and Social Mixing: Towards an Inclusive Urban Renaissance? Urban Studies, 45(12), 2449-2470. 
Mallach, A. (2008) Managing Neighbourhood Change: A Framework for Sustainable and Equitable Revitalization. New Jersey, National Housing Institute.

Manchester Independent Economic Review (MIER) (2009) Reviewer's Report. Manchester, MIER. Meen, G. (2009) 'Modelling local spatial poverty traps in England' Housing Studies, 24(1), 127-147. Norman, P. (2010) 'Identifying change over time in small area socio-economic deprivation' Applied Spatial Analysis and Policy, 3, 107-138.

Noble, M. Wright, G. Smith, G. and Dibben, C. (2006) 'Measuring multiple deprivation at the smallarea level' Environment and Planning A, 38, 169-185.

Orford, S. (2004) 'Identifying and comparing changes in the spatial concentrations of urban poverty and affluence: a case study of inner London' Computers, Environments and Urban Systems, 28 (6), 701-717.

Park, R.E. (1936) 'Human Ecology' American Journal of Sociology, XLII, 1-15.

Quercia, R.G. and Galster, G. (2000) 'Threshold Effects and Neighbourhood Change' Journal of Planning Education and Research, 20, 146-162.

Rae, A. (2012) 'Spatially Concentrated Deprivation in England: An Empirical Assessment' Regional Studies, 46(9), 1183-1199.

Reibel, M. and Regelson, M. (2007) 'Quantifying Neighbourhood Racial and Ethnic Transition Clusters in Multiethnic Cities' Urban Geography, 28(4), 361-376.

Robson, B., Bradford M.G. and Deas I. (1999) 'Beyond the boundaries: vacancy chains and the evaluation of urban development corporations' Environment and Planning A, 31(4), 647-664

Robson, B., Lymperopoulou, K. and Rae, A. (2008) 'People on the move: exploring the functional roles of deprived neighbourhoods' Environment and Planning A, 40(11), 2693-2714.

Russell, G., Stowe, P., Twomey, J. and Robson, B. (2009) Sustainable Communities: Manchester Independent Economic Review. Manchester, MIER.

Séguin, A-M., Apparicio, P. and Riva, M. (2012) 'Identifying, mapping and modelling trajectories of poverty at neighbourhood level: The case of Montréal, 1986-2006' Applied Geography, 35, 265-274. Schelling, T.C. (1971) 'Dynamic models of segregation' Journal of Mathematical Sociology, 1, $143-$ 186.

Schultz Baing, A. and Wong, C. (2012) 'Brownfield Residential Development: What Happens to the Most Deprived Neighbourhoods in England?' Urban Studies, 49(14), 2989-3008.

Schwirian, K.P. (1983) 'Models of Neighbourhood Change' Annual Review of Sociology, 9, 83-102. Squires, G. (2009) 'The Regeneration of Low Demand Neighbourhoods: The Housing Market Renewal Experience' Unpublished PhD Thesis. Manchester, University of Manchester.

Swyngedouw, E., Moulaert, F. and Rodriguez, A. (2002) 'Neoliberal Urbanisation in Europe: LargeScale Urban Development Projects and the New Urban Policy' Antipode 34(3), 380-404.

Teernstra, A.B. and Van Gent, W.P.C. (2012) 'Puzzling Patterns in Neighborhood Change: Upgrading and Downgrading in Highly Regulated Urban Housing Markets' Urban Geography, 33 (1), 91-119. Temkin, K. and Rohe, W. (1996) 'Neighbourhood Change and Urban Policy' Journal of Planning Education and Research, 15, 159-170.

Turcu, C. (2012) 'Local experiences of urban sustainability: Researching Housing Market Renewal interventions in three English neighbourhoods' Progress in Planning, 78(3), 101-150.

Van Ham, M., Hedman, L., Manley, D., Coulter, R. and Östh, J. (2014) 'Intergenerational transmission of neighbourhood poverty: an analysis of neighbourhood histories of individuals' Transactions of the Institute of British Geographers, 39, 402-417.

Webster, C. 'The Nature of the Neighbourhood' Urban Studies, 40(13), 2591-2612.

Wurdock, C. (1981) 'Neighbourhood Racial Transition: A Study in the Role of White flight' Urban Affairs Quarterly, 17, 75-89. 


\footnotetext{
'An exception is the English Economic Deprivation Index (EDI) published in 2012. This was a deprivation index that was produced using a consistent methodology in order to track Income and Employment deprivation between 2001 and 2009. For more on the use of the EDI with regard to urban policy, see Rae, (2012).

ii The definition of 'short', 'medium' and 'long-run' is relative depending on the analysis and the timeframe it covers. For example, the 'long-run' in an analysis that covers a ten-year horizon - 8-10 years perhaps - is likely to be considered 'short-run' in an analysis of change over a 50 year time-horizon.

iii There have been various revisions to the IMD in 1998, 2000, 2004, 2007 and 2010.

iv This was because the 2004 IMD was the first IMD produced at LSOA level and it corresponded most closely with the 2001 baseline from which neighbourhood change was measured in this study.

${ }^{v}$ Although not a feature of this analysis, it is possible to adjust these values to test how changing the thresholds affects the definition of change states and the subsequent form of the transition pathways.

${ }^{v i}$ Testing revealed that a $15 \%$ outlier threshold was appropriate to maintain the quality of the cluster solutions. The number of solutions was not constrained at any point in the analysis.

vii Overdispersion is when there is more variance in the data than would be predicated by the multinomial model.

viii The new Labour government introduced an ambitious brownfield reuse target in 1998 that covered all previously developed land. The intention was that at least 60 per cent of all new-built housing in England would be on brownfield land by 2008. This target was achieved eight years ahead of schedule (Schultz-Baing and Wong, 2012).

${ }^{\mathrm{ix}}$ The standard errors for all categories in the independent variables were below 1.
} 